\title{
Costs of treatment with biologic and targeted synthetic disease-modifying anti-rheumatic drugs in rheumatic diseases - data from the Romanian Registry of Rheumatic Diseases
}

\author{
Catalin Codreanu',2, Claudiu C. Popescu ${ }^{1,2}$, Bogdan Baleanu ${ }^{3}$, Corina Mogosan ${ }^{1,2}$ \\ 1"Dr. Ion Stoia" Clinical Center for Rheumatic Diseases, Romania \\ 2"Carol Davila" University of Medicine and Pharmacy, Bucharest, Romania \\ ${ }^{3}$ Romanian Registry of Rheumatic Diseases, Bucharest, Romania
}

\begin{abstract}
Given the limited resources of the health system, rheumatologists are interested in reducing the costs of modern treatments for rheumatoid arthritis, ankylosing spondylitis and psoriatic arthritis, given that the therapeutic targets are obtained and maintained. Data from the Romanian Registry of Rheumatic Diseases (RRBR, in Romanian) from 2016 to 2019 showed for all three diseases that: continuations on the same regimen with tapering experienced a marked increase; the yearly drug cost per patient steadily decreased towards 2019; adalimumab and etanercept originators present the most number of administrations per year and consequently the highest afferent costs in the entire observation period; new drugs (biologic biosimilars and targeted synthetic drugs) are gaining specific portions of the market; switches decrease costs of treatment since the hypothetical models in which switches would not have been performed and patients would have continued their previous treatment throughout the respective year showed $11 \%$ increases of costs. RRBR data have shown that reaching and maintaining therapeutic targets (including by switching strategies), reducing risks of adverse events by reducing exposure (tapering) and increasing the use of biosimilar biologics lead to significant cost reductions.
\end{abstract}

Keywords: Romanian Registry of Rheumatic Diseases, costs, biologics, biosimilars

\section{INTRODUCTION}

The importance of maintaining costs at a sustainable level for the health system is due to the fact that innovative therapies have greater efficacy, but also much higher costs than traditional treatment, their impact on health systems, even the wealthy ones, being significant. For this reason, the authorities, as well as prescribing physicians, should be interested in controlling the costs for new therapies [1-10]. The advent of modern therapeutic molecules and availability of data derived from the Romanian Registry of Rheumatic Diseases (RRBR) allowed for cost estimation on a national level, which this study aims to report.

In Romania, patients with rheumatoid arthritis (RA), ankylosing spondylitis (AS) and psoriatic arthritis (PsA) are evaluated by senior attending rheumatologists in a clinical setting (hospital, day care or outpatient clinic) and, if treatment with biologic or targeted synthetic disease-modifying anti-rheumatic drugs (bDMARDs, tsDMARDs) is indicated and the patient fulfils severity criteria issued by the National Health Insurance House (NHIH), their data are uploaded into the RRBR database in the form of a visit, capturing the doctor's indication and posology of $\mathrm{b} /$ tsDMARDs per visit, followed by issuing a reimbursed prescription which is filled by any community pharmacy. RRBR does not record actual data on issued and filled prescriptions, but data reported by each attending physician regarding decisions on bDMARDs indications. Each visit entered in the RRBR database is either an initiation visit (patients naïve to $b / t s D M A R D s$ who will receive a specific reimbursed b/tsDMARD), an initial monitoring visit (patients on a b/tsDMARD from non-reimbursed sources, such as completed clinical trials), a contin- 
uation visit (patients who will continue their previous reimbursed b/tsDMARD) or a switch visit (patients with adverse events, primary or secondary non-responders who will change their previous reimbursed b/tsDMARD). More specifically, the analysis started from the number of patients in the RRBR for which visits lead to b/tsDMARD therapy indications, which were classified into the following cost groups:

a) number of initiations (b/tsDMARD-naïve patients starting treatment within the reporting interval);

b) number of initiations followed by switch (patients who, after initiation on a specific $\mathrm{b} / \mathrm{tsD}$ MARD, switched to another $b /$ tsDMARD at the first re-evaluation because of adverse events or primary non-responder status);

c) number of continuations on the same regimen (patients who continue treatment with the same bDMARD, without changing the frequency of administration or dose);

d) number of continuations with increased dose or decreased interval of administration (patients who continue the treatment with the same b/tsDMARD, increasing the dose ordecreasing the administration interval);

e) number of continuations with reduced dose or increased interval of administration (tapering: patients who continue treatment with the same $b /$ tsDMARD, decreasing the dose or increasing the administration interval);

f) number of simple switches (patients who switched their previously continued b/tsDMARD because of adverse events or secondary non-responder status);

g) number of multiple switches (patients who, in the course of 12 months, had more than one simple switch).

\section{COST CALCULATION ALGORITHM}

For this analysis, initial monitoring visits were considered continuations with or without switch, taking into account that the patient started bDMARD therapy in the past, without being registered in the RRBR. Precautions have been taken to prevent multiple registrations so that a unique patient identifier can only be found in one of the above categories, as well as to avoid incomplete reporting, so that the total number of patients with reported visits during the period of interest to be found in the sum of the categories mentioned above. For cost calculation, the price used for each b/tsDMARD (trade name) was according to CANAMED (the national catalogue of prices for medicines for human use issued with medical prescription, authorized for marketing) in effect at that date and it was expressed in the national currency (lei).

The cost analysis was performed in August 2019 for the 2016-2018 period and in February 2020 for all of 2019, using a calculation model that is described below. The analysis considered all three indications for b/tsDMARDs therapy in rheumatology as indicated (RA, AS and PsA) and it was performed using data from the RRBR, for each calendar year, respectively for the period January $1^{\text {st }} 2016$ - December $31^{\text {st } 2019 .}$

To allow the correct comparison of therapeutic costs of b/tsDMARDs, both for initiations and continuations, as well as between therapies, the cost of b/tsDMARDs was calculated taking into account strictly the period and the interval of administration introduced in the RRBR by the attending physician, for each $b / t s D M A R D$. For the real cost calculation per patient, the cost is calculated taking into account each administration scheme and its duration of administration, stated in the RRBR by the attending physician. Each administration schedule has a calculated price which took into account the price per dose multiplied by the number of doses. Exceptions were intravenous tocilizumab (administrated in doses according to the bodyweight stated in the RRBR) and rituximab (the number of administrations was calculated taking into account the "Certify that, after this visit, the patient will receive rituximab in the next 4 weeks" field from the "Medication Page" of RRBR, where it exists, or taking into account the criteria for re-administration of rituximab according to the national guidelines issued by the NHIH).

The data are taken from the last valid visit of each year, as follows:

a) from the "History of b/tsDMARD treatment" page,

1) if there is no price change during that year,

- the calculation model for simple regimen only (maintenance doses only) is according to the "Administration regimen" page, namely the number of administrations from the respective year is calculated as the duration of administration in days from "History of b/tsDMARD treatment" page divided by the number of administration days related to the regimen, resulting in the 
cost for the entire administration period which is calculated as the number of administrations multiplied by the cost of an administration.

- the calculation model for composite regimens (loading doses followed by maintenance doses) is according to the "Administration regimen" page, namely the number of loading administrations and the number of maintenance administrations for the reporting year. Each type of administration (loading and maintenance) has a calculated cost taking into account the number of administrations and the cost of an administration. The total cost for that administration period is the sum of the loading cost and the maintenance cost.
2) if there is a change in price during that year, the same above calculation algorithm is used, but the cost is calculated for each period of a b/tsDMARD price.

b) from "Recommended b/tsDMARD treatment" page, the duration of administration is calculated on the same model as above, but the end date of administration period is set as December $31^{\text {st }}$ of the reporting year, and the start date of administration is set as either the date of consultation, if it is a continuation visit, or as the end date, if it is an initiation or switch visit.

For cost calculation, prices for every b/tsDMARDs listed alphabetically are reported in the national currency (lei) in Table 1: for example, Cosentyx (trade name for secukinumab) conditioned in prefilled doses of $150 \mathrm{mg}$ had a price of 3,190 lei from January $1^{\text {st2 }} 2016$ to December $8^{\text {th }} 2017,2,549$

TABLE 1. Prices per unit (lei) per b/tsDMARD

\begin{tabular}{|c|c|c|c|c|}
\hline & 2016 & 2017 & 2018 & 2019 \\
\hline Benepali (50 mg) & 784 & 784 & 784 & 740 \\
\hline Cimzia (200 mg) & 1,860 & $\begin{array}{c}\text { Jan1 } 1^{\text {st }}-J u l 17^{\text {th }}: 1,860 \\
\text { Jul1 } 17^{\text {th }}-\text { Dec3 } 31^{\text {st: }}: 1,666\end{array}$ & 1,666 & 1,630 \\
\hline Cosentyx (150 mg) & 3,190 & $\begin{array}{c}\text { Jan } 1^{\text {st }}-\operatorname{Dec} 8^{\text {th }}: 3,190 \\
\operatorname{Dec}^{\text {th }}-\operatorname{Dec} 31^{\text {st. }}: 2,549\end{array}$ & 2,549 & 2,355 \\
\hline Enbrel (25 mg) & 497 & 496 & 496 & 440 \\
\hline Enbrel (50 mg) & 976 & $\begin{array}{l}\text { Jan } 1^{\text {st }-J u n} 1^{\text {st: }}: 976 \\
\text { Jun1 } 1^{\text {st }}-\operatorname{Dec} 31^{\text {st }}: 938\end{array}$ & 938 & 825 \\
\hline Hulio (40 mg) & - & - & - & 1,218 \\
\hline Humira (40 mg) & 1,957 & 1,957 & 1,957 & $\begin{array}{c}\text { Jan } 1^{\text {st }}-\text { Feb2 } 28^{\text {th }}: 1,965 \\
\text { Mar1 } 1^{\text {st }}-J u n 30^{\text {th }}: 1,461 \\
\text { Jul } 1^{\text {st }}-\text { Dec } 31^{\text {st }}: 1,339\end{array}$ \\
\hline Hyrimoz $(40 \mathrm{mg})$ & - & - & - & 1,339 \\
\hline Imraldi (40 mg) & - & - & - & 1,116 \\
\hline Inflectra (100 mg) & 1,568 & 1,568 & 1,568 & 1,075 \\
\hline MabThera (500 mg) & 5,088 & 5,088 & $\begin{array}{l}\operatorname{Jan} 1^{\text {st }}-\operatorname{Nov} 30^{\text {th }}: 5,088 \\
\operatorname{Dec} 1^{\text {st }}-\operatorname{Dec} 31^{\text {st }}: 4,582\end{array}$ & $\begin{array}{l}\text { Jan1 } 1^{\text {st }-J a n 31} 1^{\text {st }}: 4,582 \\
\text { Feb1 } 1^{\text {st }}-O c t 30^{\text {th }}: 4,937 \\
\text { Nov1 }^{\text {st }}-D e c 31^{\text {st }}: 4,582\end{array}$ \\
\hline Olumiant (4 mg) & - & - & 166 & $\begin{array}{l}\text { Jan } 1^{\text {st }}-\operatorname{Nov} 30^{\text {th }}: 128 \\
\text { Dec1 }^{\text {st }}-\operatorname{Dec} 31^{\text {st }}: 110\end{array}$ \\
\hline Orencia (125 mg) & 983 & 983 & 983 & 1,488 \\
\hline Remicade (100 mg) & 2,162 & 1,824 & $\begin{array}{c}\text { Jan1 } 1^{\text {st }-A u g 1} 1^{\text {st }}: 1,824 \\
\text { Aug2 }^{\text {ndd }}-\operatorname{Dec} 31^{\text {st: }}: 1,809\end{array}$ & $\begin{array}{c}\text { Jan1 } 1^{\text {st }} \text { Jul31 } 1^{\text {st }}: 1,233 \\
\text { Aug1 } 1^{\text {st }}-\text { Dec31 } \\
\text { st: }\end{array}$ \\
\hline Remsima (100 mg) & 1,593 & 1,593 & 1,593 & $\begin{array}{l}\text { Jan1 } 1^{\text {st }} \text { Jul31 } 1^{\text {st }}: 1,233 \\
\text { Aug1 } 1^{\text {st }}-D e c 31^{\text {st: }}: 1,290\end{array}$ \\
\hline RoActemra (162 mg) & 1,050 & 1,050 & 1,050 & 1,056 \\
\hline RoActemra (80 mg) & 649 & 649 & 649 & 605 \\
\hline RoActemra (200 mg) & 1,509 & 1,509 & 1,509 & 1,407 \\
\hline RoActemra (400 mg) & 2,908 & 2,908 & 2,908 & 2,743 \\
\hline Simponi (50 mg) & 3,998 & 3988 & 3,988 & 3,859 \\
\hline Xeljanz (5 mg) & - & - & - & 64 \\
\hline Zessly (100 mg) & - & - & - & $\begin{array}{c}\text { Jan1 } 1^{\text {st }}-J u l 31^{\text {st }}: 1,233 \\
\text { Aug1 } 1^{\text {st }}-\operatorname{Dec} 31^{\text {st: }}: 1,290\end{array}$ \\
\hline
\end{tabular}


lei from December $9^{\text {th }} 2017$ to December $31^{\text {st }} 2018$ and 2,355 lei respectively in 2019. For Euro comparisons, according to the National Bank of Romanian, the average exchange rates were: $4.4908 \mathrm{Lei} /$ Euro in 2016; 4.5681 Lei/Euro in 2017; 4.6535 Lei/Euro in 2018; 4.7452 Lei/Euro in 2019.

The above calculation produced the real costs of $\mathrm{b} / \mathrm{tsDMARDs}$ for each year in the analysed period. Since there have been initiatives to alter the switch mechanism based on the hypothesis that switching b/tsDMARDs increases costs, this study also aimed to test this hypothesis using RRBR data. Therefore, a second hypothetical calculation aimed to estimate costs without switches, namely the overall costs assuming that patients who underwent switches, before the first switch, would have continued throughout the year with their previous b/tsDMARD. For the calculation of this "no-switch" hypothetical cost, the data from "History of b/tsDMARD treatment" RRBR pages were used for the first $b / t s D M A R D$ administered in the reference year. The last administration date is December $31^{\text {st }}$ of the reporting year and the first administration date is the existing date in the "History of b/tsDMARD treatment" RRBR page, or January $1^{\text {stif }}$ the first administration was performed in the previous year. For patients who started the year directly with a switch, the cost was considered identical to the real cost: in 2019 there were 241 such cases, in 2018, 91 cases, 40 cases in 2017 and 78 cases in 2016. The no-switch model also assumed that each patient continued treatment using the last administration regimen of the previous year.

\section{COSTS OF RA TREATMENT WITH b/tsDMARDs}

In 2019, compared to the previous years, both the number of RA patients and treatment decisions (initiations, continuations and switches) increased significantly (Table 2). Of note, continuations on tapering regimes experienced a marked increase towards 2019: from $0.1 \%$ of patients in 2016 to $0.4 \%$ in 2017 , $1.4 \%$ in 2018 and $2.6 \%$ in 2019 (Figure 1).

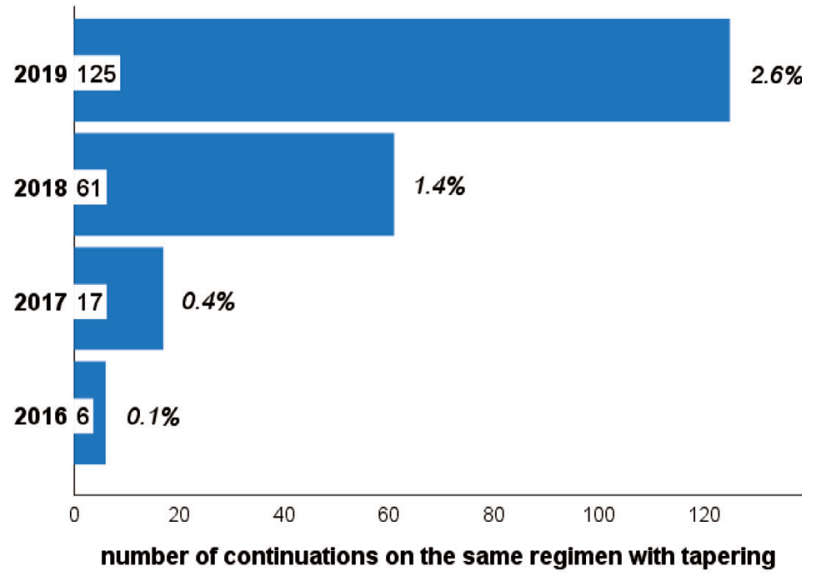

FIGURE 1. The number of continuations on the same regimen with tapering in each investigated year in $R A$ patients. Percentages represent the fraction from the total number of RRBR patients with $R A$ in each year $(4,375$ in 2016, 4,081 in 2017, 4,470 in 2018 and 4,726 in 2019)

TABLE 2. Number of RA patients in RRBR according to treatment decision (initiation - i; continuation - $c$; switch $-s$ )

\begin{tabular}{|l|c|c|c|c|}
\hline & $\mathbf{2 0 1 6}$ & $\mathbf{2 0 1 7}$ & $\mathbf{2 0 1 8}$ & $\mathbf{2 0 1 9}$ \\
\hline initiations (i) & $\mathbf{5 2 8 ( 1 2 . 1 \% )}$ & $\mathbf{3 6 5}(\mathbf{8 . 9 \% )}$ & $\mathbf{5 0 1 ( 1 1 . 2 \% )}$ & $\mathbf{5 7 3}(\mathbf{1 2 . 1 \% )}$ \\
\hline i without c & $285(6.5 \%)$ & $225(5.5 \%)$ & $293(6.6 \%)$ & $289(6.1 \%)$ \\
\hline i followed by c & $212(4.9 \%)$ & $115(2.8 \%)$ & $165(3.7 \%)$ & $249(5.3 \%)$ \\
\hline i followed by s & $31(0.7 \%)$ & $25(0.6 \%)$ & $43(1.0 \%)$ & $35(0.7 \%)$ \\
\hline continuations (c) & $\mathbf{3 , 2 7 8 ( 7 4 . 9 \% )}$ & $\mathbf{3 , 2 9 5 ( 8 0 . 7 \% )}$ & $\mathbf{3 , 3 8 2 ( 7 5 . 7 \% )}$ & $\mathbf{3 , 5 3 4}(\mathbf{7 4 . 8 \% )}$ \\
\hline c on same regimen & $3,226(73.7 \%)$ & $3,127(76.6 \%)$ & $3,164(70.8 \%)$ & $3,360(71.1 \%)$ \\
\hline classical regimen & $3,211(73.4 \%)$ & $3,101(76.0 \%)$ & $3,096(69.3 \%)$ & $3,230(68.4 \%)$ \\
\hline tapering regimen & $6(0.1 \%)$ & $17(0.4 \%)$ & $61(1.4 \%)$ & $125(2.6 \%)$ \\
\hline increased exposure & $9(0.2 \%)$ & $9(0.2 \%)$ & $7(0.2 \%)$ & $5(0.1 \%)$ \\
\hline $\mathbf{c}$, increased exposure & $21(0.5 \%)$ & $50(1.2 \%)$ & $72(1.6 \%)$ & $64(1.4 \%)$ \\
\hline $\mathbf{c}$, decreased exposure & $31(0.7 \%)$ & $118(2.9 \%)$ & $146(3.3 \%)$ & $110(2.3 \%)$ \\
\hline switch (s) & $\mathbf{5 6 9 ( 1 3 . 0 \% )}$ & $\mathbf{4 2 1 ( 1 0 . 3 \% )}$ & $\mathbf{5 8 7 ~ ( 1 3 . 1 \% )}$ & $\mathbf{6 1 9} \mathbf{( 1 3 . 1 \% )}$ \\
\hline simple s & $528(12.1 \%)$ & $378(9.3 \%)$ & $542(12.1 \%)$ & $565(12.0 \%)$ \\
\hline multiple s & $41(0.9 \%)$ & $43(1.1 \%)$ & $45(1.0 \%)$ & $54(1.1 \%)$ \\
\hline total & $\mathbf{4 , 3 7 5}$ & $\mathbf{4 , 0 8 1}$ & $\mathbf{4 , 4 7 0}$ & $\mathbf{4 , 7 2 6}$ \\
\hline
\end{tabular}

- increased exposure refers to dose augmentation of decreased interval between administrations, while decreased exposure refers to dose diminution of increased interval between administrations; 
Concordant with the rise in patient numbers, the costs of initiations and continuations (including tapered regimens) increased towards 2019, while switches maintained a comparable level throughout the analysed period (Table 3). Interestingly, taking into account all treatment decisions from 2016 to 2019 , the cost per patient decreased: from a maximum of 36,067 lei/patient in 2017 (approximately 7,895 euros/patient at the average exchange rate in 2017) to a minimum of 33,612 lei/patient in 2019 (approximately 7,083 euros/patient at the average exchange rate in 2019; Figure 2).

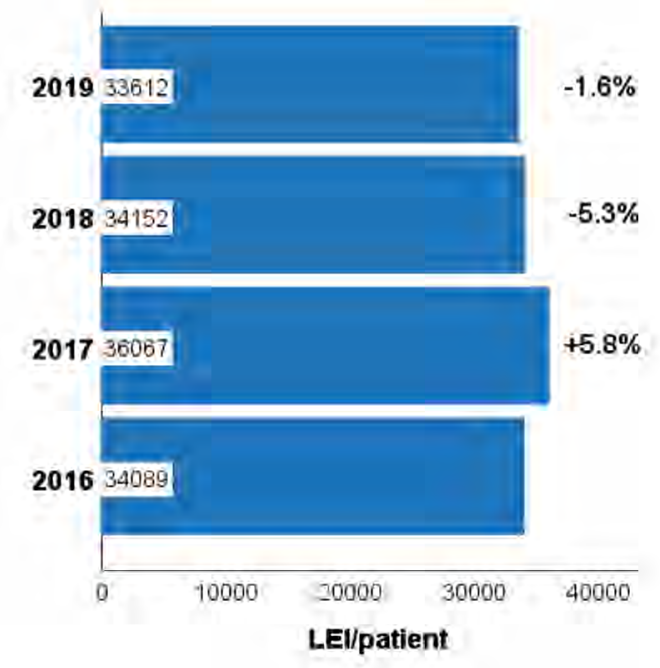

FIGURE 2. The cost of treatment per RA patient (lei) in each year, taking into account all treatment decisions from 2016 to 2019. Positive and negative percentages represent variations from the previous year to the next
Regarding the costs of specific b/tsDMARDs (Table 4), Enbrel (etanercept originator) is the leading drug in terms of number of administrations and afferent costs in the entire observation period (Table 4): in $2019,22.7 \%$ of the cohort's administrations were with Enbrel, accounting for $24.6 \%$ of total cost, with similar figures in 2018 (27.6\% of administrations and $30.3 \%$ of total cost), 2017 (29.0\% of administrations and $33.3 \%$ of total cost) and 2016 (31.6\% of administrations and $37.5 \%$ of total cost).

The second position, with the same constancy over the 4 investigated years, is Humira (adalimumab originator) which accounted for $20.0 \%$ of the 2019 administrations and $20.3 \%$ of its total cost, with similar levels in the previous years $(24.6 \%$ of administrations and $27.6 \%$ of total cost in 2018, $24.6 \%$ of administrations and $28.7 \%$ of total cost in $2017,25.6 \%$ of administrations and $30.6 \%$ of total cost in 2016). Together, these two bDMARDs explained $45 \%$ of total costs in 2019 and more than half of total costs between 2016 and 2018 .

The third position in terms of prevalence and cost was disputed between MabThera (rituximab originator, which accounted for $17.3 \%$ of administrations and $8.9 \%$ of total cost in 2016 , respectively $13.7 \%$ of administrations and $6.9 \%$ of total cost in 2017) and RoActemra (tocilizumab) which gained weight progressively, reaching $11.4 \%$ of administrations and $12.6 \%$ of total cost in 2018 and respectively $12.7 \%$ of administrations and $16.9 \%$ of total cost in 2019 .

TABLE 3. Real cost of RA treatment in RRBR according to treatment decision (initiation - i; continuation - c; switch - s)

\begin{tabular}{|c|c|c|c|c|}
\hline & $2016(n=4,375)$ & $2017(n=4,081)$ & $2018(n=4,470)$ & $2019(n=4,726)$ \\
\hline initiations (i) & $11,812,753$ (7.9\%) & $7,038,836(4.8 \%)$ & $9,540,342(6.3 \%)$ & $11,053,873(7.0 \%)$ \\
\hline i without c & $4,420,079$ (3.0\%) & $3,030,813(2.1 \%)$ & $3,557,172(2.3 \%)$ & $3,072,252(1.9 \%)$ \\
\hline i followed by c & $6,516,754(4.4 \%)$ & $3,438,466(2.3 \%)$ & $4,753,520(3.1 \%)$ & $7,043,351(4.4 \%)$ \\
\hline i followed by s & $875,919(0.6 \%)$ & $569,558(0.4 \%)$ & $1,229,650(0.8 \%)$ & $938,270(0.6 \%)$ \\
\hline continuations (c) & $117,256,429$ (78.6\%) & $124,040,214$ (84.3\%) & $121,361,313$ (79.5\%) & $126,731,580(79.8 \%)$ \\
\hline c on same regimen & $11,506,127$ (77.2\%) & $116,482,676$ (79.1\%) & $112,374,346(73.6 \%)$ & $120,700,127$ (76.0\%) \\
\hline classical regimen & $114,351,114(76.7 \%)$ & $115,499,694(78.5 \%)$ & $110,063,920(72.1 \%)$ & $117,070,083(73.7 \%)$ \\
\hline tapering regimen & $254,007(0.2 \%)$ & $643,184(0.4 \%)$ & $2,057,981$ (1.4\%) & $3,336,644(2.1 \%)$ \\
\hline increased exposure & $456,146(0.3 \%)$ & $339,799(0.2 \%)$ & $252,446(0.2 \%)$ & $293,400(0.2 \%)$ \\
\hline c, increased exposure & $912,354(0.6 \%)$ & $2,383,689(2.1 \%)$ & $3,211,124(2.1 \%)$ & $2,409,250(1.5 \%)$ \\
\hline c, decreased exposure & $1,282,808(0.9 \%)$ & $5,173,849(3.8 \%)$ & $5,775,843(3.8 \%)$ & $3,622,203(2.3 \%)$ \\
\hline switch (s) & $20,071,877$ (13.5\%) & $16,111,905$ (10.9\%) & $21,756,643(14.3 \%)$ & $21,064,742(13.3 \%)$ \\
\hline simple $\mathbf{s}$ & $18,565,839(12.5 \%)$ & $14,419,819(9.8 \%)$ & $20,245,416(13.3 \%)$ & $19,211,927$ (12.1\%) \\
\hline multiple $\mathbf{s}$ & $1,506,038(1.0 \%)$ & $1,692,086(1.2 \%)$ & $1,511,227(1.0 \%)$ & $1,852,815(1.2 \%)$ \\
\hline total & $149,141,058$ & $147,190,955$ & $152,658,298$ & $158,850,195$ \\
\hline cost/patient & 34,089 & 36,067 & 34,152 & 33,612 \\
\hline
\end{tabular}

- increased exposure refers to dose augmentation of decreased interval between administrations, while decreased exposure refers to dose diminution of increased interval between administrations;

- continuations on the same regimen refers to patients who all year had the same classical, tapered or increased exposure, while continuations with increased/decreased exposure refers to patients who had the same molecule all year but changed exposure during that year. 
TABLE 4. Real cost of RA treatment in RRBR according to b/tsDMARD trade names

\begin{tabular}{|c|c|c|c|c|}
\hline & 2019 & & 2018 & \\
\hline & $n(\%)$ & cost (\%) lei & $n(\%)$ & cost (\%) lei \\
\hline Benepali & $488(5.6 \%)$ & $7,642,245$ (4.8\%) & $236(3.2 \%)$ & $3,170,399$ (2.1\%) \\
\hline Cimzia & $585(6.7 \%)$ & $11,385,037(7.2 \%)$ & 603 (8.1\%) & $11,488,437(7.5 \%)$ \\
\hline Enbrel & $1,978(22.7 \%)$ & $39,115,310(24.6 \%)$ & $2,061(27.6 \%)$ & $46,192,742(30.3 \%)$ \\
\hline Hulio & $27(0.3 \%)$ & $233,791(0.2 \%)$ & - & - \\
\hline Humira & $1,743(20.0 \%)$ & $32,264,767(20.3 \%)$ & $1,836(24.6 \%)$ & $42,188,886(27.6 \%)$ \\
\hline Hyrimoz & $32(0.4 \%)$ & $300,046(0.2 \%)$ & - & - \\
\hline Imraldi & $10(0.1 \%)$ & $44,650(0.03 \%)$ & - & - \\
\hline Inflectra & $40(0.5 \%)$ & $335,272(0.2 \%)$ & $82(1.1 \%)$ & $1,228,991(0.8 \%)$ \\
\hline MabThera & $910(10.4 \%)$ & $8,828,661(5.6 \%)$ & 515 (6.9\%) & $5,222,466(3.4 \%)$ \\
\hline Olumiant & $507(5.8 \%)$ & $8,271,920(5.2 \%)$ & $81(1.1 \%)$ & $651,691(0.4 \%)$ \\
\hline Orencia & $259(3.0 \%)$ & $6,457,181(4.1 \%)$ & $363(4.9 \%)$ & $8,676,488(5.7 \%)$ \\
\hline Remicade & $219(2.5 \%)$ & $2,274,308(1.4 \%)$ & $273(3.7 \%)$ & $4,124,352(2.7 \%)$ \\
\hline Remsima & $245(2.8 \%)$ & $2,596,914(1.6 \%)$ & $212(2.8 \%)$ & $2,622,144(1.7 \%)$ \\
\hline RoActemra & $1,107(12.7 \%)$ & $26,818,417$ (16.9\%) & $853(11.4 \%)$ & $19210486(12.6 \%)$ \\
\hline Simponi & $373(4.3 \%)$ & $8,691,481(5.5 \%)$ & $349(4.7 \%)$ & $7,881,217(5.2 \%)$ \\
\hline Xeljanz & $190(2.2 \%)$ & $3,571,363(2.3 \%)$ & - & - \\
\hline Zessly & $2(0.02 \%)$ & $18,833(0.01 \%)$ & - & - \\
\hline \multirow[t]{3}{*}{ total } & 8,715 & $158,850,195$ & 7,464 & $152,658,298$ \\
\hline & \multicolumn{2}{|c|}{2017} & 2016 & \\
\hline & $n(\%)$ & $\operatorname{cost}(\%)$ lei & $n(\%)$ & cost (\%) lei \\
\hline Benepali & $26(0.4 \%)$ & $161,539(0.1 \%)$ & - & - \\
\hline Cimzia & $559(7.7 \%)$ & $11,297,010(7.7 \%)$ & $473(6.3 \%)$ & $8,309,971(5.6 \%)$ \\
\hline Enbrel & $2,121(29.0 \%)$ & $48,990,398(33.3 \%)$ & $2,396(31.6 \%)$ & $55,875,088(37.5 \%)$ \\
\hline Humira & $1,796(24.6 \%)$ & $42,275,176(28.7 \%)$ & $1,942(25.6 \%)$ & $45,644,355(30.6 \%)$ \\
\hline Inflectra & $97(1.3 \%)$ & $1,266,613$ (0.9\%) & $96(1.3 \%)$ & $1,302,667$ (0.9\%) \\
\hline MabThera & $1,001(13.7 \%)$ & $10,186,276(6.9 \%)$ & $1,308(17.3 \%)$ & $13,310,339(8.9 \%)$ \\
\hline Orencia & $431(5.9 \%)$ & $9,516,021(6.5 \%)$ & $352(4.7 \%)$ & $5,868,868(3.9 \%)$ \\
\hline Remicade & $339(4.6 \%)$ & $5,162,951(3.5 \%)$ & $414(5.5 \%)$ & $7,912,298(5.3 \%)$ \\
\hline Remsima & $161(2.2 \%)$ & $2,141,046(1.5 \%)$ & $123(1.6 \%)$ & $1,688,622(1.1 \%)$ \\
\hline RoActemra & $496(6.8 \%)$ & $10,183,300(6.9 \%)$ & 267 (3.5\%) & $5,479,687(3.7 \%)$ \\
\hline Simponi & $284(3.9 \%)$ & $6,010,624(4.1 \%)$ & $202(2.7 \%)$ & $3,749,162(2.5 \%)$ \\
\hline total & 7,311 & $147,190,954.86$ & 7,573 & $149,141,058.07$ \\
\hline
\end{tabular}

- the table reports for each specific year: the number of patients with at least one administration, its proportion from the total number of patients, the cost of each $b / t s D M A R D$ trade name and its proportion from the total cost;

- the total number of administrations is greater than the total number of patients in a specific year because some patients received more than one $b / t s D M A R D s$ during a specific year.

Similar to the rise of RoActemra, but with lower proportions, Simponi (golimumab) recorded an increase from a minimum of $2.7 \%$ of administrations and $2.5 \%$ of total costs in 2016 to a maximum of $4.3 \%$ of administrations and $5.5 \%$ of total costs in 2019.

Aside from MabThera, there were other molecules which experienced a negative balance during the 4 investigated years, such as Orencia (abatacept, which decreased from a maximum of $5.9 \%$ of administrations and $6.5 \%$ of total costs in 2017 to a minimum of $3.0 \%$ of administrations and $4.1 \%$ of total costs in 2019) and Remicade (infliximab originator, which decreased from a maximum of $5.5 \%$ of administrations and $5.3 \%$ of total costs in 2016 to $2.5 \%$ of administrations and $1.4 \%$ of total costs in 2019).

While some molecules exhibited a relative stable balance over the 2016-2019 in terms of number of patients and costs (such as Cimzia, Table 4), it was expected that the new drugs (bDMARD biosimilars and tsDMARDs) to gain specific portions of the market.

Thus, Benepali (biosimilar etanercept), since it became available in Romania in 2017 as the only biosimilar etanercept, increased from $0.4 \%$ of administrations and $0.1 \%$ of total cost in its first year, to $5.6 \%$ of administrations and $4.8 \%$ of total cost in 
2019, surpassing classical molecules such as Remicade, Simponi and Orencia. From the total number of administrations and costs accounted by etanercept, biosimilar and originator, Benepali covered $1.2 \%$ of administrations and $0.3 \%$ of costs in 2017 , increasing 9-fold in 2018 (10.3\% of administrations and $6.4 \%$ of costs) and doubling in 2019 (19.8\% of administrations and $16.3 \%$ of costs; Figure 3 ).

A similar pattern emerged for infliximab: from the total number of administrations and costs accounted by infliximab, biosimilar and originator, biosimilars (Inflectra, Remsima and Zessly in 2019 and Inflectra and Remsima in 2016-2018) increased progressively from 2016 (34.6\% of administrations and $27.4 \%$ of costs) with about $10 \%$ on each domain, reaching $43.2 \%$ of administrations and $39.8 \%$ of costs in $2017,51.9 \%$ of administrations and $48.3 \%$ of costs in 2018 and respectively $56.7 \%$ of administrations and $56.5 \%$ of costs in 2019 (Figure 3).

In its first year with available biosimilars, already $3.8 \%$ of administrations and $1.8 \%$ of costs are accounted by adalimumab biosimilars (Hulio, Imraldi, Hyrimoz) compared to the total number of administrations on adalimumab (biosimilar and originator). Also, treatment with tsDMARDs (Olumiant and Xeljanz) increased almost 8-fold from 2018 when reimbursed tsDMARDs became available in Romania and when they accounted for only $1.1 \%$ of administrations and $0.4 \%$ of total costs, to 2019 when tsDMARDs accounted for $8.0 \%$ of administrations and $7.5 \%$ of total costs.

The hypothetical model in which switches would not have been performed and patients would have continued their previous b/tsDMARD throughout the respective year, before the first switch was made, produces significant results which invalidates the assumption that switches increase costs of treatment: the "no-switch" model would have generated at least $11 \%$ more costs each year (Table 5).

TABLE 5. Real cost versus no-switch cost in RA

\begin{tabular}{|l|c|c|c|c|}
\hline & 2016 & 2017 & 2018 & 2019 \\
\hline real cost & $20,947,796$ & $16,681,463$ & $22,986,294$ & $22,003,012$ \\
\hline $\begin{array}{l}\text { "no- } \\
\text { switch" } \\
\text { model }\end{array}$ & $24,671,483$ & $19,593,130$ & $25,717,481$ & $24,450,864$ \\
\hline variation & $+17.8 \%$ & $+17.5 \%$ & $+11.9 \%$ & $+11.1 \%$ \\
\hline
\end{tabular}

- the no-switch cost is a hypothetical model in which switches would not have been performed and patients would have continued their previous $b / t s D M A R D$ throughout the respective year, before the first switch was made composed in 2019 from simple switches (21,113,380 lei), multiple switches (2,335,550 lei) and initiations followed by switch $(1,001,934$ lei); in 2018 from simple switches (22,579,590 lei), multiple switches (1,882,231 lei) and initiations followed by switch (1,255,661 lei); in 2017 from simple switches $(16,926,050$ lei), multiple switches $(1,991,441$ lei) and initiations followed by switch (675,638 lei); in 2016 from simple switches (21,921,331 lei), multiple switches (1,842,360 lei) and initiations followed by switch $(907,792$ lei)

- prices are reported in the national currency (lei), for comparison, according to the National Bank of Romanian, the average exchange rates are as follows: 4.4908 lei/euro in 2016; 4.5681 lei/euro in 2017; 4.6535 lei/euro in 2018; 4.7452 lei/euro in 2019.

\section{COSTS OF AS TREATMENT WITH bDMARDs}

In 2019, compared to the previous years, both the number of AS patients and treatment decisions (continuations and switches) increased significantly, while initiations fluctuated around the mean (Table 6). Of note, continuations on tapering regimes experienced a marked increase towards 2019: from 1.1\%
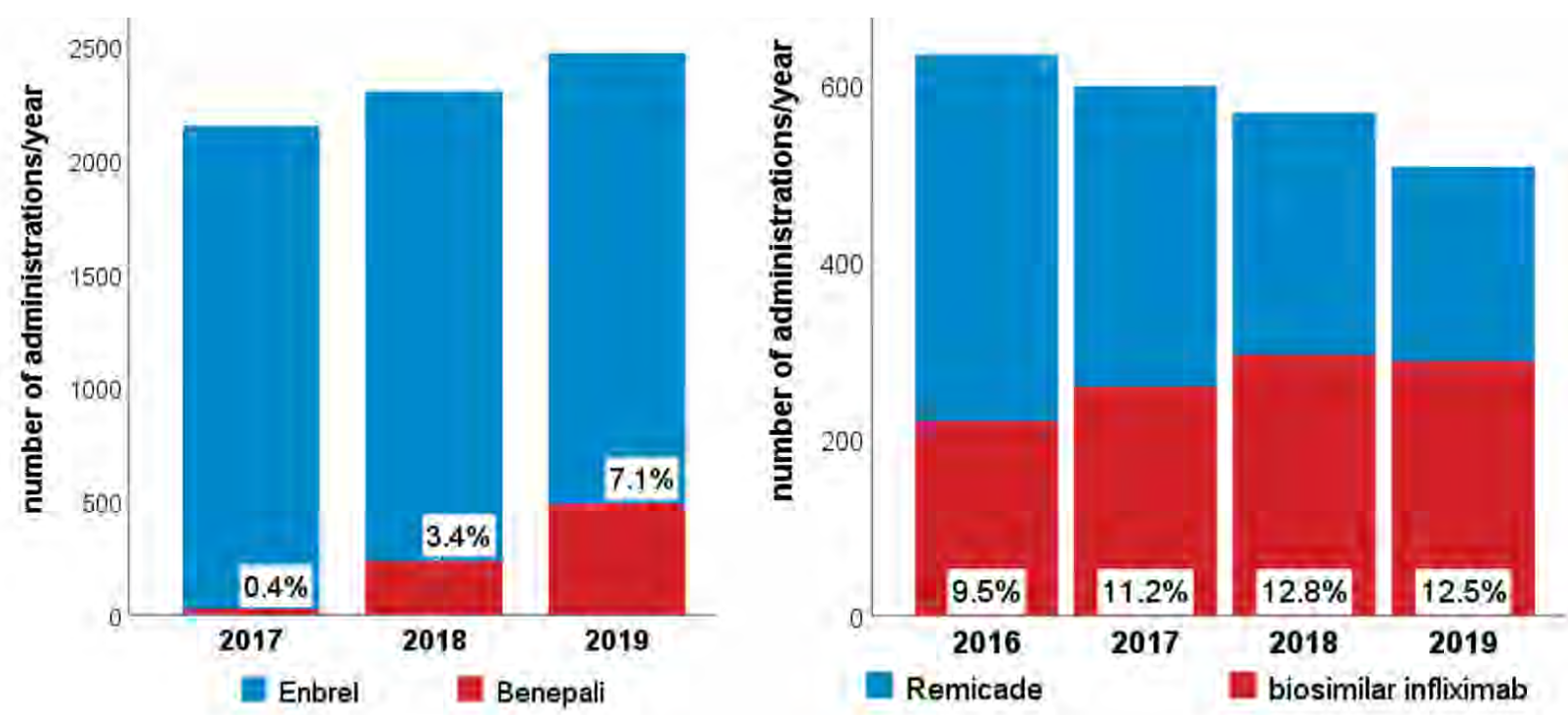

FIGURE 3. Comparison of number of administrations/year between originator and biosimilar etanercept (Enbrel versus Benepali, left) and infliximab (Remicade versus Inflectra, Remsima and Zessly, right) in RA patients 
TABLE 6. Number of AS patients in RRBR according to treatment decision (initiation - $i$; continuation - $c$; switch $-s$ )

\begin{tabular}{|c|c|c|c|c|}
\hline & 2016 & 2017 & 2018 & 2019 \\
\hline initiations (i) & $343(11.0 \%)$ & $242(7.8 \%)$ & 390 (11.2\%) & 376 (10.1\%) \\
\hline i without c & $163(5.3 \%)$ & $116(3.7 \%)$ & $176(5.1 \%)$ & $183(4.9 \%)$ \\
\hline i followed by c & $167(5.4 \%)$ & $119(3.8 \%)$ & $189(5.4 \%)$ & $186(5.0 \%)$ \\
\hline i followed by s & $13(0.4 \%)$ & $7(0.2 \%)$ & $25(0.7 \%)$ & $7(0.2 \%)$ \\
\hline continuations (c) & $2,556(82.3 \%)$ & $2,594(83.3 \%)$ & $2,738(78.7 \%)$ & $3,006(80.9 \%)$ \\
\hline c on same regimen & $2,486(80.0 \%)$ & $2,409(77.4 \%)$ & $2,454(70.5 \%)$ & $2,754(74.2 \%)$ \\
\hline classical regimen & $2,452(78.9 \%)$ & $2,364(75.9 \%)$ & $2,340(67.2 \%)$ & $2,548(68.6 \%)$ \\
\hline tapering regimen & $33(1.1 \%)$ & $41(1.3 \%)$ & $110(3.2 \%)$ & $200(5.4 \%)$ \\
\hline increased exposure & $1(0.03 \%)$ & $4(0.1 \%)$ & $4(0.1 \%)$ & $6(0.2 \%)$ \\
\hline c, increased exposure & $27(0.9 \%)$ & $22(0.7 \%)$ & $64(1.8 \%)$ & $87(2.3 \%)$ \\
\hline c, decreased exposure & $43(1.4 \%)$ & $163(5.2 \%)$ & $220(6.3 \%)$ & $165(4.4 \%)$ \\
\hline switch (s) & 207 (6.7\%) & 278 (8.9\%) & 352 (10.1\%) & $332(8.9 \%)$ \\
\hline simple $\mathbf{s}$ & $191(6.1 \%)$ & $249(8.0 \%)$ & $308(8.9 \%)$ & $301(8.1 \%)$ \\
\hline multiple s & $16(0.5 \%)$ & $29(0.9 \%)$ & $44(1.3 \%)$ & $31(0.8 \%)$ \\
\hline total & 3,106 & 3,114 & 3,480 & 3,714 \\
\hline
\end{tabular}

- increased exposure refers to dose augmentation of decreased interval between administrations, while decreased exposure refers to dose diminution of increased interval between administrations;

- continuations on the same regimen refers to patients who all year had the same classical, tapered or increased exposure, while continuations with increased/decreased exposure refers to patients who had the same bDMARD all year but changed exposure during that year.

of patients in 2016 to $1.3 \%$ in $2017,3.2 \%$ in 2018 and 5.4\% in 2019 (Figure 4).

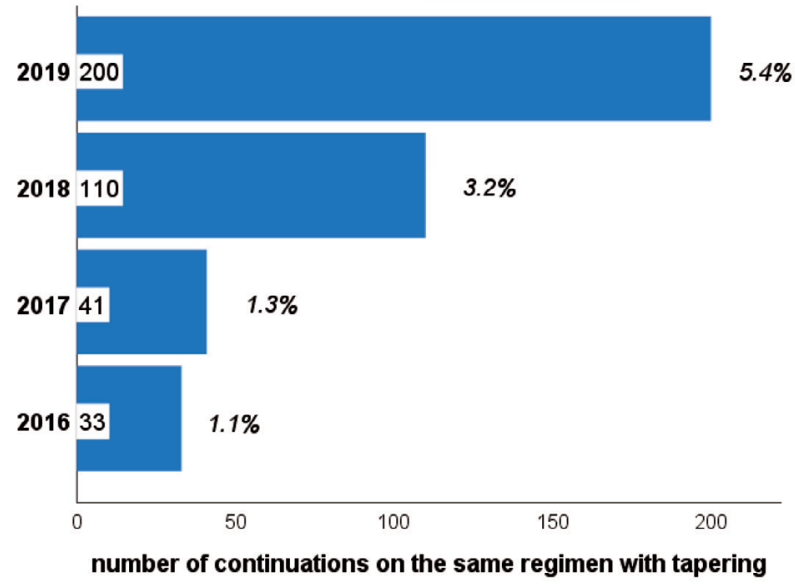

FIGURE 4. The number of continuations on the same regimen with tapering in each investigated year in AS patients. Percentages represent the fraction from the total number of RRBR patients with AS in each year (3,106 in 2016, 3,114 in 2017, 3,480 in 2018 and 3,714 in 2019)

Concordant with the rise in patient numbers, the costs of continuations (including tapered regimens) and switches increased towards 2019, while the costs of initiations fluctuated from a minimum in 2017 to a maximum in 2018 (Table 7). Interestingly, taking into account all treatment decisions from 2016 to 2019 , the cost per patient decreased: from a maximum of 46,899 lei/patient in 2016 (approximately 10,443 euros/patient at the average exchange rate in 2016) to a minimum of 36,791 lei/patient in 2019 (approximately 7,753 euros/patient at the average exchange rate in 2019; Figure 5).

Regarding the costs of specific bDMARDs (Table 8), Humira (adalimumab originator) is the leading drug in terms of number of administrations and afferent costs in the entire observation period (Table 8 ): in $2019,32.2 \%$ of the cohort's administrations were with Humira, accounting for $31.7 \%$ of total cost, with similar figures in 2018 (35.1\% of administrations and $36.9 \%$ of total cost), 2017 (37.8\% of administrations and $39.3 \%$ of total cost) and 2016 (39.3\% of administrations and $38.1 \%$ of total cost).

The second position, very close to Humira, with the same constancy over the 4 investigated years, is Enbrel (etanercept originator) which accounted for $28.0 \%$ of the 2019 administrations and $30.0 \%$ of its total cost, with similar levels in the previous years (30.7\% of administrations and $31.4 \%$ of total cost in $2018,34.8 \%$ of administrations and $34.9 \%$ of total cost in 2017 , respectively $36.7 \%$ of administrations and $35.5 \%$ of total cost in 2016). Together, these two bDMARDs explained $62 \%$ of total costs in 2019, $68 \%$ of total costs in 2018 , peaking at $74 \%$ of total costs in 2016 and 2017.

The third position in terms of prevalence and cost was disputed between Remicade (infliximab originator, which accounted for $11.3 \%$ of administrations and $12.3 \%$ of total cost in 2016 , respectively $13.5 \%$ of administrations and $17.7 \%$ of total cost in 2017) and Simponi (golimumab) which gained weight pro- 
TABLE 7. Real cost of AS treatment in RRBR according to treatment decision (initiation - $i$; continuation $-c$; switch $-s$ )

\begin{tabular}{|c|c|c|c|c|}
\hline & $2016(n=3,106)$ & $2017(n=3,114)$ & $2018(n=3,480)$ & $2019(n=3,714)$ \\
\hline initiations (i) & $8,792,661(6.0 \%)$ & $5,709,241(4.0 \%)$ & $9,982,813(6.6 \%)$ & $7,883,481(5.8 \%)$ \\
\hline i without c & $2,718,263$ (1.9\%) & $1,826,501(1.3 \%)$ & $2,902,886(1.9 \%)$ & $2,424,118(1.8 \%)$ \\
\hline i followed by c & $5,609,326(3.9 \%)$ & $3,651,768(2.6 \%)$ & $6,190,021(4.1 \%)$ & $5,233,968(3.8 \%)$ \\
\hline i followed by s & $465,071(0.3 \%)$ & $230,973(0.2 \%)$ & $889,906(0.6 \%)$ & $225,395(0.2 \%)$ \\
\hline continuations (c) & $\begin{array}{c}127,321,846 \\
(87.4 \%)\end{array}$ & $\begin{array}{c}124,238,390 \\
(87.2 \%)\end{array}$ & $\begin{array}{c}126,500,942 \\
(84.1 \%)\end{array}$ & $\begin{array}{c}116,585,558 \\
(85.3 \%)\end{array}$ \\
\hline c on same regimen & $\begin{array}{c}123,912,515 \\
(85.1 \%)\end{array}$ & $\begin{array}{c}116,058,248 \\
(81.5 \%)\end{array}$ & $\begin{array}{c}115,403,596 \\
(76.7 \%)\end{array}$ & $\begin{array}{c}108,548,316 \\
(79.4 \%)\end{array}$ \\
\hline classical regimen & $\begin{array}{c}122,413,795 \\
(84.0 \%)\end{array}$ & $\begin{array}{c}114,211,249 \\
(80.2 \%)\end{array}$ & $\begin{array}{c}111,228,685 \\
(74.0 \%)\end{array}$ & $\begin{array}{c}102,879,389 \\
(75.3 \%)\end{array}$ \\
\hline tapering regimen & $1,402,996(1.0 \%)$ & $1,539,887(1.1 \%)$ & $3,799,995(2.5 \%)$ & $5,105,447(3.7 \%)$ \\
\hline increased exposure & $95,723(0.1 \%)$ & $307,112(0.2 \%)$ & $374,916(0.3 \%)$ & $563,480(0.4 \%)$ \\
\hline c, increased exposure & $1,448,087(1.0 \%)$ & $1,127,441(0.8 \%)$ & $2,899,319(1.9 \%)$ & $3,184,029(2.33 \%)$ \\
\hline $\begin{array}{l}\text { c, decreased } \\
\text { exposure }\end{array}$ & $1,961,245$ (1.4\%) & $7,052,701$ (5.0\%) & $8,198,028(5.5 \%)$ & $4,853,214(3.6 \%)$ \\
\hline switch (s) & $9,553,808(\%)$ & $12,547,979(\%)$ & $13,917,398(\%)$ & $12,173,737$ (\%) \\
\hline simple $\mathbf{s}$ & $8,812,785$ (6.1\%) & $11,107,947(7.8 \%)$ & $12,240,462(8.1 \%)$ & $11,007,604(8.1 \%)$ \\
\hline multiple $\mathbf{s}$ & $741,023(0.5 \%)$ & $1,440,032(1.0 \%)$ & $1,676,936(1.1 \%)$ & $1,166,133$ (0.9\%) \\
\hline total & $145,668,316$ & $142,495,611$ & $150,401,153$ & $136,642,777$ \\
\hline cost/patient & 46,899 & 45,760 & 43,219 & 36,791 \\
\hline
\end{tabular}

- increased exposure refers to dose augmentation of decreased interval between administrations, while decreased exposure refers to dose diminution of increased interval between administrations;

- continuations on the same regimen refers to patients who all year had the same classical, tapered or increased exposure, while continuations with increased/decreased exposure refers to patients who had the same molecule all year but changed exposure during that year.

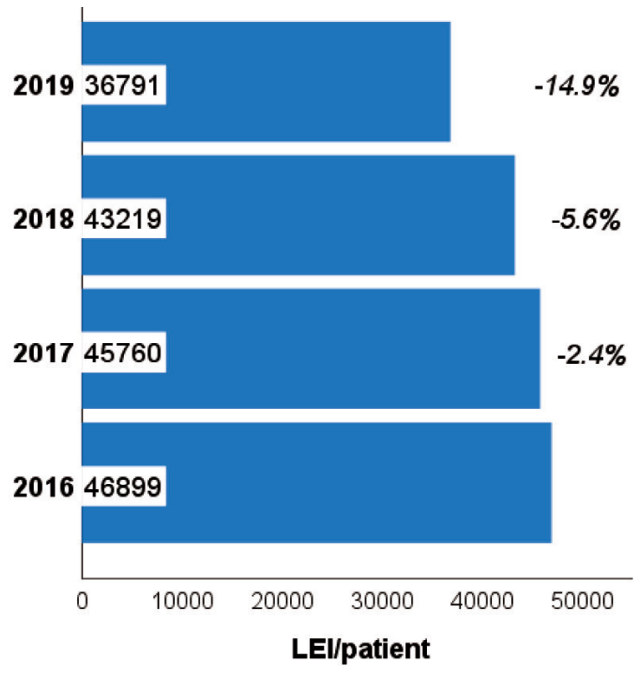

FIGURE 5. The cost of treatment per AS patient (lei) in each year, taking into account all treatment decisions from 2016 to 2019. Negative percentages represent variations from the previous year to the next

gressively, reaching $9.6 \%$ of administrations and $10.0 \%$ of total cost in 2018 and respectively $9.8 \%$ of administrations and $12.6 \%$ of total cost in 2019 . Similar to the rise of Simponi, but with lower proportions, Cosentyx (secukinumab) recorded an increase from a minimum of $1.8 \%$ of administrations and $1.3 \%$ of total costs in 2017 to a maximum of
9.4\% of administrations and $7.4 \%$ of total costs in 2019. Similarly, Cimzia (certolizumab) recorded an increase from a minimum of $1.1 \%$ of administrations and $0.6 \%$ of total costs in 2017 to a maximum of $3.1 \%$ of administrations and $3.0 \%$ of total costs in 2019 .

As expected, new drugs (bDMARD biosimilars) started to gain significant portions of the market of AS treatment.

Thus, Benepali (biosimilar etanercept), since it became available in Romania in 2017 as the only biosimilar etanercept, increased from $0.3 \%$ of administrations and $0.1 \%$ of total cost in its first year, to $4.7 \%$ of administrations and $4.0 \%$ of total cost in 2019, surpassing classical molecules such as Cimzia. From the total number of administrations and costs accounted by etanercept, biosimilar and originator, Benepali covered $1.0 \%$ of administrations and $0.3 \%$ of costs in 2017, increasing 7-fold in 2018 (7.4\% of administrations and $4.8 \%$ of costs) and doubling in 2019 (14.5\% of administrations and $11.7 \%$ of costs; Figure 6 ).

A similar pattern emerged for infliximab: from the total number of administrations and costs accounted by infliximab, biosimilar and originator, biosimilars (Inflectra, Remsima and Zessly in 2019 and Inflectra and Remsima in 2016-2018) increased 
progressively from 2016 (19.4\% of administrations and $14.4 \%$ of costs) with about $5 \%$ on each domain, reaching $25.1 \%$ of administrations and $21.8 \%$ of costs in $2017,31.4 \%$ of administrations and $28.5 \%$ of costs in 2018 and respectively $36.0 \%$ of administratons and $34.7 \%$ of costs in 2019 (Figure 6).

TABLE 8. Real cost of AS treatment in RRBR according to bDMARD trade names

\begin{tabular}{|c|c|c|c|c|}
\hline & 2019 & & 2018 & \\
\hline & $n(\%)$ & $\operatorname{cost}(\%)$ lei & $n(\%)$ & $\operatorname{cost}(\%)$ lei \\
\hline Benepali & $352(4.7 \%)$ & $5,453,569(4.0 \%)$ & $171(2.5 \%)$ & $2,390,934(1.6 \%)$ \\
\hline Cimzia & $230(3.1 \%)$ & $4,137,346(3.0 \%)$ & $144(2.1 \%)$ & $2,148,041(1.4 \%)$ \\
\hline Cosentyx & 697 (9.4\%) & $10,166,017(7.4 \%)$ & $458(6.6 \%)$ & $6,554,742(4.4 \%)$ \\
\hline Enbrel & $2,080(28.0 \%)$ & $41,042,131(30.0 \%)$ & $2,134(30.7 \%)$ & $47,147,018(31.4 \%)$ \\
\hline Hulio & $6(0.1 \%)$ & 47,489 (0.03\%) & - & - \\
\hline Humira & $2,389(32.2 \%)$ & $43,311,876(31.7 \%)$ & $2,445(35.1 \%)$ & $55,565,280(36.9 \%)$ \\
\hline Hyrimoz & $38(0.5 \%)$ & $345,588(0.3 \%)$ & - & - \\
\hline Imraldi & $9(0.1 \%)$ & $30,139(0.02 \%)$ & - & - \\
\hline Inflectra & $88(1.2 \%)$ & $1,226,107(0.9 \%)$ & $129(1.9 \%)$ & $2,633,551(1.8 \%)$ \\
\hline Remicade & $566(7.6 \%)$ & $9,669,038$ (7.1\%) & $643(9.2 \%)$ & $15,382,063(10.2 \%)$ \\
\hline Remsima & 231 (3.1\%) & $3,913,582(2.9 \%)$ & $166(2.4 \%)$ & $3,495,130(2.3 \%)$ \\
\hline Simponi & $728(9.8 \%)$ & $17,178,412(12.6 \%)$ & $671(9.6 \%)$ & $15,084,394(10.0 \%)$ \\
\hline Zessly & $7(0.1 \%)$ & $121,483(0.1 \%)$ & - & - \\
\hline \multirow[t]{3}{*}{ total } & 7,421 & $136,642,777$ & 6,961 & $150,401,153$ \\
\hline & \multicolumn{2}{|c|}{2017} & 2016 & \\
\hline & $n(\%)$ & cost (\%) lei & $n(\%)$ & cost (\%) lei \\
\hline Benepali & $21(0.3 \%)$ & $141,151(0.1 \%)$ & - & - \\
\hline Cimzia & 65 (1.1\%) & $871,066(0.6 \%)$ & - & - \\
\hline Cosentyx & $111(1.8 \%)$ & $1,818,941$ (1.3\%) & - & - \\
\hline Enbrel & $2,162(34.8 \%)$ & $49,727,017$ (34.9\%) & $2,240(36.7 \%)$ & $51,726,637(35.5 \%)$ \\
\hline Humira & $2,348(37.8 \%)$ & $55,243,189(38.8 \%)$ & 2,397 (39.3\%) & $55,427,105(38.1 \%)$ \\
\hline Inflectra & 117 (1.9\%) & $2,508,144(1.8 \%)$ & $100(1.6 \%)$ & $2,163,274(1.5 \%)$ \\
\hline Remicade & 703 (11.3\%) & $17,491,299(12.3 \%)$ & $821(13.5 \%)$ & $25,723,615(17.7 \%)$ \\
\hline Remsima & $118(1.9 \%)$ & $2,378,409(1.7 \%)$ & $98(1.6 \%)$ & $2,160,162(1.5 \%)$ \\
\hline Simponi & $569(9.2 \%)$ & $12,316,395(8.6 \%)$ & $450(7.4 \%)$ & $8,467,522(5.8 \%)$ \\
\hline total & 6,214 & $142,495,611$ & 6,106 & $145,668,316$ \\
\hline
\end{tabular}

- the table reports for each specific year: the number of patients with at least one administration, its proportion from the total number of patients, the cost of each b/tsDMARD trade name and its proportion from the total cost;

- the total number of administrations is greater than the total number of patients in a specific year because some patients received more than one $b / t s D M A R D s$ during a specific year.
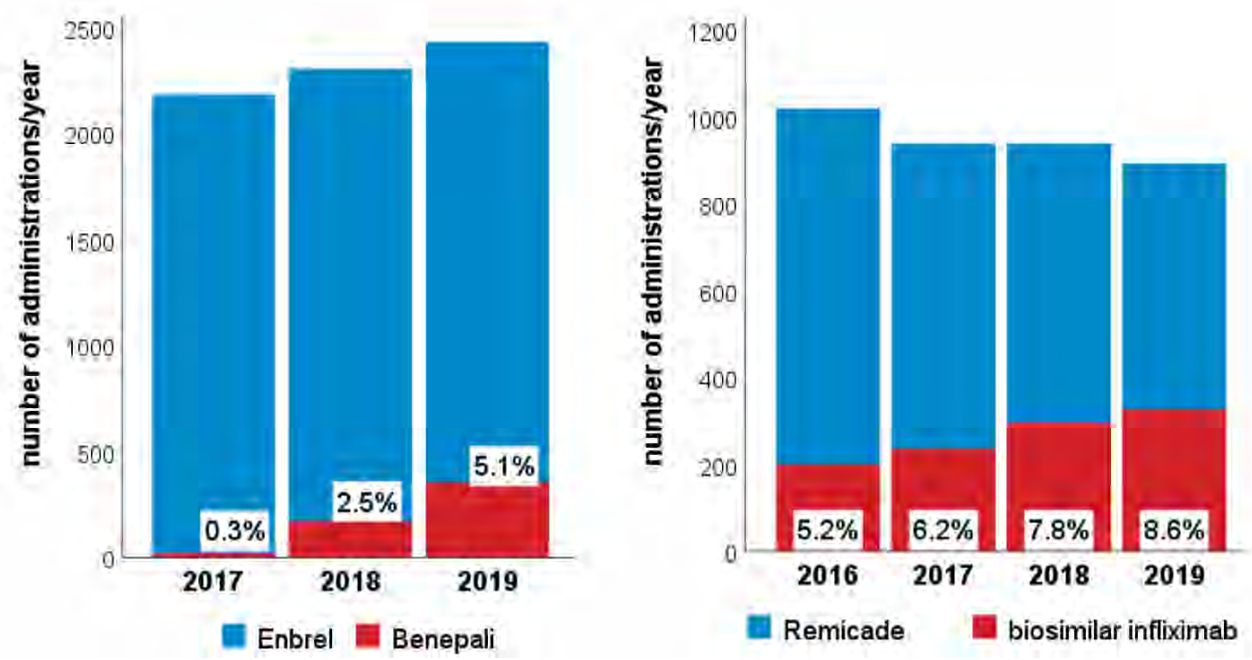

FIGURE 6. Comparison of number of administrations/year between originator and biosimilar etanercept (Enbrel versus Benepali, left) and infliximab (Remicade versus Inflectra, Remsima and Zessly, right) in AS patients 
The hypothetical model in which switches would not have been performed and patients would have continued their previous bDMARD throughout the respective year, before the first switch was made, produces significant results which invalidates the assumption that switches increase costs of treatment: the "no-switch" model would have generated at least 5\% more costs for 2016-2018 (Table 9).

TABLE 9. Real cost versus no-switch cost in AS

\begin{tabular}{|l|c|c|c|c|}
\hline & 2016 & 2017 & 2018 & 2019 \\
\hline real cost & $10,018,880$ & $12,778,952$ & $14,807,304$ & $12,399,132$ \\
\hline $\begin{array}{l}\text { "no- } \\
\text { switch" } \\
\text { model }\end{array}$ & $11,212,213$ & $13,424,536$ & $16,533,433$ & $12,409,429$ \\
\hline variation & $+11.9 \%$ & $+5.1 \%$ & $+11.7 \%$ & $+0.1 \%$ \\
\hline
\end{tabular}

- the no-switch cost is a hypothetical model in which switches would not have been performed and patients would have continued their previous bDMARD throughout the respective year, before the first switch was made composed in 2019 from simple switches (10,989,729 lei), multiple switches $(1,214,788$ lei) and initiations followed by switch (204,912 lei); in 2018, from simple switches (13,719,129 lei), multiple switches $(1,942,290$ lei) and initiations followed by switch $(872,044$ lei); in 2017, from simple switches $(11,803,004$ lei), multiple switches $(1,398,217$ lei) and initiations followed by switch ( 223,315 lei); in 2016 , from simple switches $(9,916,404$ lei), multiple switches $(866,894$ lei) and initiations followed by switch $(428,914$ lei).

\section{COSTS OF PSA TREATMENT WITH bDMARDs}

In 2019, compared to the previous years, both the number of PsA patients and treatment decisions (in- itiations and switches) increased significantly, while continuations fluctuated around the mean (Table 10). Of note, continuations on tapering regimes experienced a marked increase towards 2019: from $0.4 \%$ of patients in 2016 to $0.5 \%$ in $2017,1.9 \%$ in 2018 and $3.7 \%$ in 2019 (Figure 7).

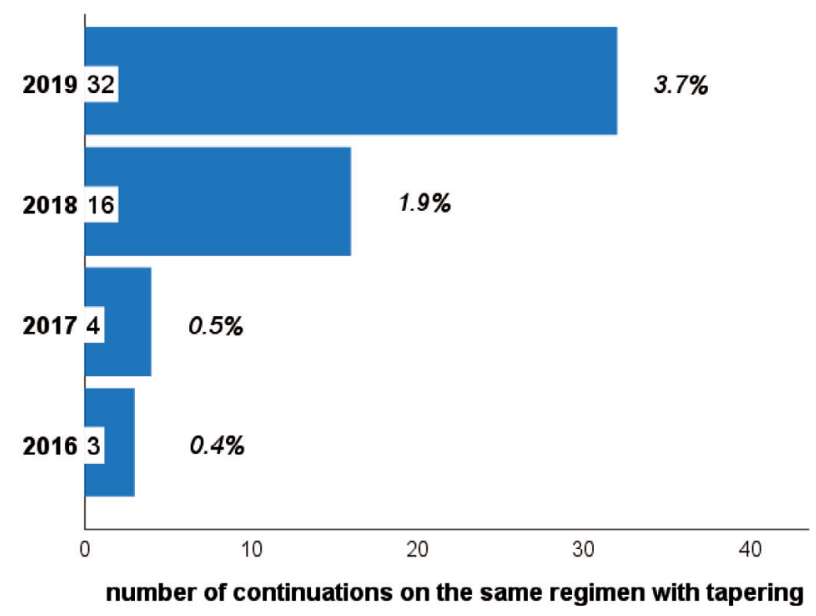

FIGURE 7. The number of continuations on the same regimen with tapering in each investigated year in PsA patients. Percentages represent the fraction from the total number of RRBR patients with PsA in each year (811 in 2016, 790 in 2017, 857 in 2018 and 871 in 2019)

Concordant with the rise in patient numbers, the costs of switches increased towards 2019, while the costs of continuations decreased significantly and

TABLE 10. Number of PSA patients in RRBR according to treatment decision (initiation - $i$; continuation $-c$; switch $-s$ )

\begin{tabular}{|l|c|c|c|c|}
\hline & $\mathbf{2 0 1 6}$ & $\mathbf{2 0 1 7}$ & $\mathbf{2 0 1 8}$ & $\mathbf{2 0 1 9}$ \\
\hline initiations (i) & $\mathbf{5 7}(\mathbf{7 . 0 \% )}$ & $\mathbf{4 9}(\mathbf{6 . 2 \% )}$ & $\mathbf{7 8 ~ ( 9 . 1 \% )}$ & $\mathbf{6 3}(\mathbf{7 . 2 \% )}$ \\
\hline i without c & $26(3.2 \%)$ & $25(3.2 \%)$ & $31(3.6 \%)$ & $38(4.4 \%)$ \\
\hline i followed by c & $29(3.6 \%)$ & $21(2.7 \%)$ & $44(5.1 \%)$ & $21(2.4 \%)$ \\
\hline i followed by s & $2(0.3 \%)$ & $3(0.4 \%)$ & $3(0.4 \%)$ & $4(0.5 \%)$ \\
\hline continuations (c) & $\mathbf{7 1 0 ( 8 7 . 5 \% )}$ & $\mathbf{6 7 6 ( 8 5 . 6 \% )}$ & $\mathbf{7 0 5 ( 8 2 . 3 \% )}$ & $\mathbf{7 1 6 ( 8 2 . 2 \% )}$ \\
\hline c on same regimen & $697(85.9 \%)$ & $643(81.4 \%)$ & $664(77.5 \%)$ & $665(76.4 \%)$ \\
\hline classical regimen & $693(85.5 \%)$ & $636(80.5 \%)$ & $641(74.8 \%)$ & $627(72.0 \%)$ \\
\hline tapering regimen & $3(0.4 \%)$ & $4(0.5 \%)$ & $16(1.9 \%)$ & $32(3.7 \%)$ \\
\hline increased exposure & $1(0.1 \%)$ & $3(0.4 \%)$ & $7(0.8 \%)$ & $6(0.7 \%)$ \\
\hline $\mathbf{c}$ increased exposure & $9(1.1 \%)$ & $10(1.3 \%)$ & $13(1.5 \%)$ & $23(2.6 \%)$ \\
\hline $\mathbf{c}$ decreased exposure & $4(0.5 \%)$ & $23(2.9 \%)$ & $28(3.3 \%)$ & $28(3.2 \%)$ \\
\hline switch (s) & $\mathbf{4 4 ( 5 . 4 \% )}$ & $\mathbf{6 5 ( 8 . 2 \% )}$ & $\mathbf{7 4 ( 8 . 6 \% )}$ & $\mathbf{9 2 ( 1 0 . 6 \% )}$ \\
\hline simple s & $43(5.3 \%)$ & $63(8.0 \%)$ & $70(8.2 \%)$ & $81(9.3 \%)$ \\
\hline multiple s & $1(0.1 \%)$ & $2(0.3 \%)$ & $4(0.5 \%)$ & $11(1.3 \%)$ \\
\hline total & $\mathbf{8 1 1}$ & $\mathbf{7 9 0}$ & $\mathbf{8 5 7}$ & $\mathbf{8 7 1}$ \\
\hline
\end{tabular}

- increased exposure refers to dose augmentation of decreased interval between administrations, while decreased exposure refers to dose diminution of increased interval between administrations;

- continuations on the same regimen refers to patients who all year had the same classical, tapered or increased exposure, while continuations with increased/decreased exposure refers to patients who had the same bDMARD all year but changed exposure during that year. 
initiations fluctuated from a maximum in 2018 to a maximum in 2019 (Table 11). Interestingly, taking into account all treatment decisions from 2016 to 2019 , the cost per patient decreased: from a maximum of 48360lei/patient in 2016 (approximately 10769 euros/patient at the average exchange rate in 2016) to a minimum of 38547lei/patient in 2019 (approximately 8123 euros/patient at the average exchange rate in 2019; Figure 8).

Regarding the costs of specific bDMARDs (Table 12), Enbrel (etanercept originator) is the leading drug in terms of number of administrations and afferent costs in the entire observation period (Table 12 ): in $2019,34.5 \%$ of the cohort's administrations were with Enbrel, accounting for $36.4 \%$ of total cost, with similar figures in 2018 (37.4\% of administrations and $37.0 \%$ of total cost), 2017 (39.8\% of administrations and $39.4 \%$ of total cost) and 2016 (41.5\% of administrations and $39.7 \%$ of total cost).

The second position, very close to Enbrel, with the same constancy over the 4 investigated years, is Humira (adalimumab originator) which accounted for $31.8 \%$ of the 2019 administrations and $30.6 \%$ of its total cost, with similar levels in the previous years (33.8\% of administrations and $34.5 \%$ of total cost in $2018,35.6 \%$ of administrations and $36.0 \%$ of total cost in 2017 , respectively $35.3 \%$ of administrations and $34.3 \%$ of total cost in 2016). Together, these two bDMARDs explained $67.0 \%$ of total costs in 2019 ,
$71.5 \%$ of total costs in 2018 , peaking at $75.4 \%$ of total costs in 2017 and $74.0 \%$ in 2016.

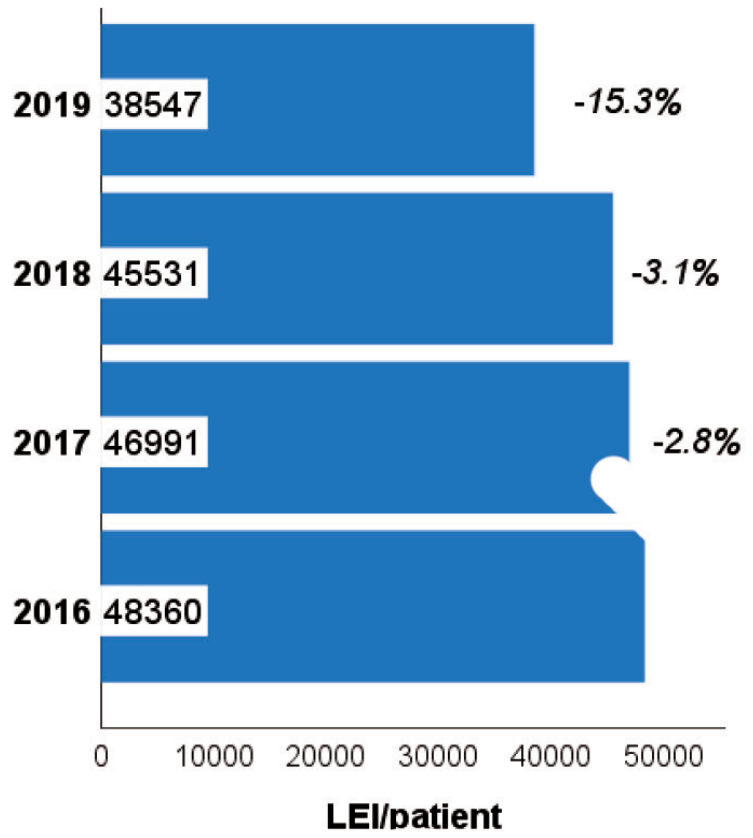

FIGURE 8. The cost of treatment per PsA patient (lei) in each year, taking into account all treatment decisions from 2016 to 2019. Negative percentages represent variations from the previous year to the next

The third position in terms of prevalence and cost was disputed between Remicade (infliximab originator, which accounted for $15.8 \%$ of administrations and $20.0 \%$ of total cost in 2016 , respectively $12.9 \%$

TABLE 11. Real cost of PSA treatment in RRBR according to treatment decision (initiation - i; continuation - c; switch $-s$ )

\begin{tabular}{|c|c|c|c|c|}
\hline & $2016(n=811)$ & $2017(n=790)$ & $2018(n=857)$ & $2019(n=871)$ \\
\hline initiations (i) & $1,469,994$ (3.8\%) & $1,218,115$ (3.3\%) & $2,129,983$ (5.5\%) & $1,109,647$ (3.3\%) \\
\hline i without c & $395,912(1.0 \%)$ & $427,762(1.2 \%)$ & $531,357(1.4 \%)$ & $466,094(1.4 \%)$ \\
\hline i followed by c & $1,015,929(2.6 \%)$ & 696,948 (1.9\%) & $1,491,136$ (3.8\%) & $554,560(1.7 \%)$ \\
\hline i followed by s & $58,153(0.2 \%)$ & $93,405(0.3 \%)$ & $107,489(0.3 \%)$ & $88,993(0.3 \%)$ \\
\hline continuations (c) & $35,615,812(90.8 \%)$ & $32,971,446(88.8 \%)$ & $33,831,782(86.7 \%)$ & $28,729,243(85.6 \%)$ \\
\hline c on same regimen & $34,922,617$ (89.0\%) & $31,402,212(84.6 \%)$ & $32,071,879(82.2 \%)$ & $26,899,659$ (80.1\%) \\
\hline classical regimen & $34,724,591(88.5 \%)$ & $30,936,699(83.3 \%)$ & $30,813,999(79.0 \%)$ & $25,450,028(75.8 \%)$ \\
\hline tapering regimen & $158,142(0.4 \%)$ & $170,366(0.5 \%)$ & $595,794(1.5 \%)$ & $855,276(2.6 \%)$ \\
\hline increased exposure & $39,885(0.1 \%)$ & $295,147(0.8 \%)$ & $662,086(1.7 \%)$ & $594,355(1.8 \%)$ \\
\hline c, increased exposure & 496,040 (1.3\%) & $539,484(1.5 \%)$ & $662,104(1.7 \%)$ & $971,534(2.9 \%)$ \\
\hline $\begin{array}{l}\text { c, decreased } \\
\text { exposure }\end{array}$ & $197,155(0.5 \%)$ & $1,029,750(2.8 \%)$ & $1,097,799(2.8 \%)$ & $858,049(2.6 \%)$ \\
\hline switch (s) & $2,134,300(5.4 \%)$ & 2,933,402 (7.9\%) & $3,058,038(7.8 \%)$ & $3,735,749$ (11.1\%) \\
\hline simple $\mathbf{s}$ & $2,097,733$ (5.4\%) & $2,840,364(7.7 \%)$ & $2,903,733$ (7.4\%) & $3,288,215$ (9.8\%) \\
\hline multiple s & $36,567(0.1 \%)$ & $93,038(0.3 \%)$ & $154,305(0.4 \%)$ & $447,534(1.3 \%)$ \\
\hline total & $39,220,105$ & $37,122,963$ & $39,019,802(\%)$ & $33,574,641$ \\
\hline cost/patient & 48,360 & 46,991 & 45,531 & 38,547 \\
\hline
\end{tabular}

- increased exposure refers to dose augmentation of decreased interval between administrations, while decreased exposure refers to dose diminution of increased interval between administrations;

- continuations on the same regimen refers to patients who all year had the same classical, tapered or increased exposure, while continuations with increased/decreased exposure refers to patients who had the same molecule all year but changed exposure during that year. 
of administrations and $13.8 \%$ of total cost in 2017) and Simponi (golimumab) which gained weight progressively, reaching $11.1 \%$ of administrations and $12.3 \%$ of total cost in 2018 and respectively $10.2 \%$ of administrations and $13.3 \%$ of total cost in 2019 . Similar to the rise of Simponi, but with lower proportions, Cosentyx (secukinumab) recorded an increase from a minimum of $0.5 \%$ of administrations and $0.3 \%$ of total costs in 2017 to a maximum of $8.3 \%$ of administrations and $6.4 \%$ of total costs in 2019.

As expected, new drugs (bDMARD biosimilars) started to gain significant portions of the market of PsA treatment.

Thus, Benepali (biosimilar etanercept), since it became available in Romania in 2017 as the only biosimilar etanercept, increased from $0.2 \%$ of administrations and $0.1 \%$ of total cost in its first year, to $4.3 \%$ of administrations and $3.6 \%$ of total cost in 2019. From the total number of administrations and costs accounted by etanercept, biosimilar and originator, Benepali covered $0.5 \%$ of administrations and
$0.2 \%$ of costs in 2017, increasing 5-fold in 2018 (5.5\% of administrations and $3.4 \%$ of costs) and doubling in 2019 (11.0\% of administrations and $9.1 \%$ of costs; Figure 9$)$.

A similar pattern emerged for infliximab: from the total number of administrations and costs accounted by infliximab, biosimilar and originator, biosimilars (Inflectra and Remsima throughout 20162019) increased progressively from 2016 (7.7\% of administrations and $6.1 \%$ of costs), reaching $8.6 \%$ of administrations and $7.4 \%$ of costs in $2017,10.3 \%$ of administrations and $10.2 \%$ of costs in 2018 and respectively $14.3 \%$ of administrations and $15.5 \%$ of costs in 2019 (Figure 9).

The hypothetical model in which switches would not have been performed and patients would have continued their previous bDMARD throughout the respective year, before the first switch was made, produces significant results which invalidates the assumption that switches increase costs of treatment: the "no-switch" model would have generated at least 8\% more costs for 2016-2018 (Table 13).

TABLE 12. Real cost of PSA treatment in RRBR according to bDMARD trade names

\begin{tabular}{|c|c|c|c|c|}
\hline & 2019 & & 2018 & \\
\hline & $n(\%)$ & $\operatorname{cost}(\%)$ lei & $n(\%)$ & cost (\%) lei \\
\hline Benepali & $74(4.3 \%)$ & $1,215,274(3.6 \%)$ & $37(2.2 \%)$ & $503,437(1.3 \%)$ \\
\hline Cosentyx & $144(8.3 \%)$ & $2,145,296(6.4 \%)$ & $62(3.6 \%)$ & $930,203(2.4 \%)$ \\
\hline Enbrel & $596(34.5 \%)$ & $12,223,124(36.4 \%)$ & 639 (37.4\%) & $14,439,601(37.0 \%)$ \\
\hline Hulio & $2(0.1 \%)$ & $15,860(0.1 \%)$ & - & - \\
\hline Humira & $548(31.8 \%)$ & $10,278,758(30.6 \%)$ & $578(33.8 \%)$ & $13,442,585(34.5 \%)$ \\
\hline Hyrimoz & $7(0.4 \%)$ & $69,654(0.2 \%)$ & - & - \\
\hline Imraldi & $1(0.1 \%)$ & $2,233(0.01 \%)$ & - & - \\
\hline Inflectra & $6(0.4 \%)$ & $87,042(0.3 \%)$ & $8(0.5 \%)$ & $181,840(0.5 \%)$ \\
\hline Remicade & $155(9.0 \%)$ & $2,674,405$ (8.0\%) & $182(10.7 \%)$ & $4,423,748(11.3 \%)$ \\
\hline Remsima & $20(1.2 \%)$ & $405,363(1.2 \%)$ & $13(0.8 \%)$ & $320,201(0.8 \%)$ \\
\hline Simponi & $173(10.2 \%)$ & $4,457,665$ (13.3\%) & $190(11.1 \%)$ & $4,778,187(12.3 \%)$ \\
\hline \multirow[t]{3}{*}{ total } & 1726 & $33,574,641$ & 1,709 & $39,019,802$ \\
\hline & \multicolumn{2}{|c|}{2017} & 2016 & \\
\hline & $n(\%)$ & cost (\%) lei & $n(\%)$ & cost (\%) lei \\
\hline Benepali & $3(0.2 \%)$ & $29,014(0.1 \%)$ & - & - \\
\hline Cosentyx & $7(0.5 \%)$ & $107,789(0.3 \%)$ & - & - \\
\hline Enbrel & $626(39.8 \%)$ & $14,615,196(39.4 \%)$ & $665(41.5 \%)$ & $15,582,357(39.7 \%)$ \\
\hline Humira & $560(35.6 \%)$ & $13,373,019(36.0 \%)$ & $565(35.3 \%)$ & $13,455,194(34.3 \%)$ \\
\hline Inflectra & $15(1.0 \%)$ & $318,221(0.9 \%)$ & $14(0.9 \%)$ & $337,032(0.9 \%)$ \\
\hline Remicade & 203 (12.9\%) & $5,117,358(13.8 \%)$ & $253(15.8 \%)$ & $7,853,928(20.0 \%)$ \\
\hline Remsima & $4(0.3 \%)$ & $92,396(0.3 \%)$ & $7(0.5 \%)$ & $168,862(0.4 \%)$ \\
\hline Simponi & $155(10.0 \%)$ & $3,469,969$ (9.4\%) & $98(6.1 \%)$ & $1,822,731(4.7 \%)$ \\
\hline total & 1,573 & $37,122,963$ & 1,602 & $39,220,105$ \\
\hline
\end{tabular}

- the table reports for each specific year: the number of patients with at least one administration, its proportion from the total number of patients, the cost of each $b / t s D M A R D$ trade name and its proportion from the total cost;

- the total number of administrations is greater than the total number of patients in a specific year because some patients received more than one $b / t s D M A R D s$ during a specific year. 


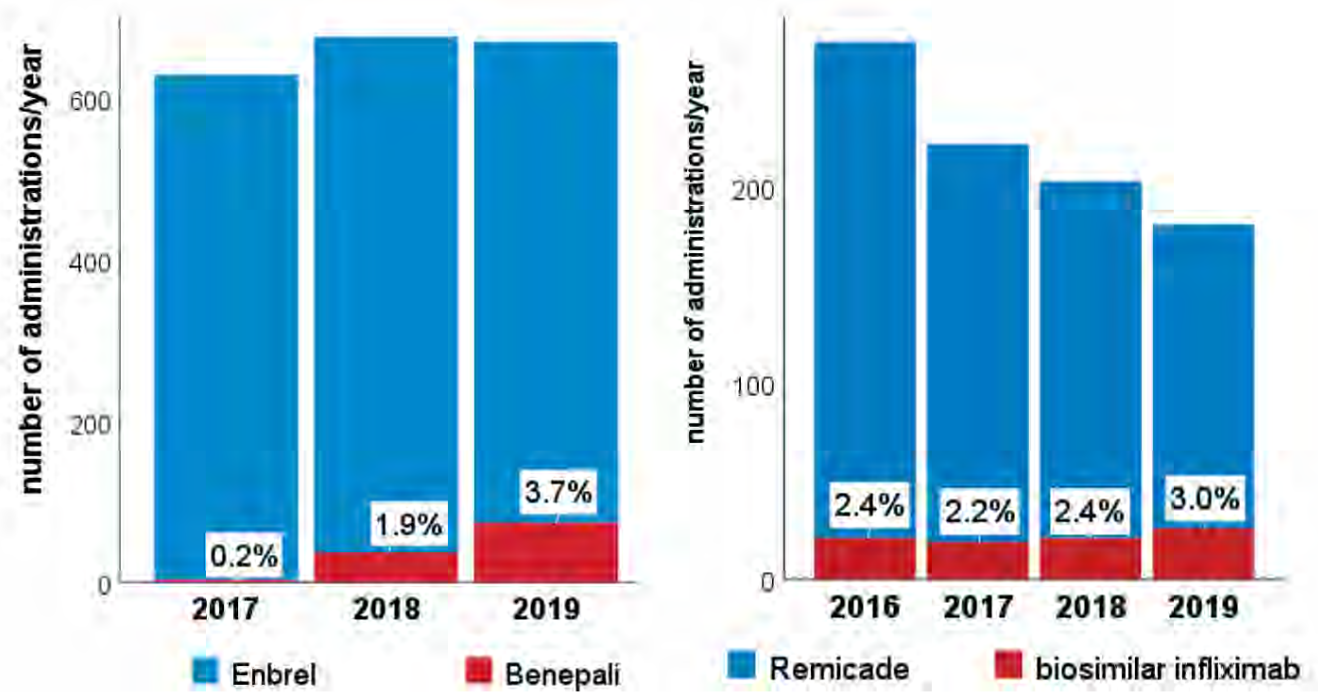

FIGURE 9. Comparison of number of administrations/years between originator and biosimilar etanercept (Enbrel versus Benepali, left) and infliximab (Remicade versus Inflectra, Remsima and Zessly, right) in PsA patients

TABLE 13. Real cost versus no-switch cost in PsA

\begin{tabular}{|l|c|c|c|c|}
\hline & 2016 & 2017 & 2018 & 2019 \\
\hline real cost & $2,192,452$ & $3,026,807$ & $3,165,527$ & $3,824,744$ \\
\hline $\begin{array}{l}\text { "no-switch" } \\
\text { model }\end{array}$ & $2,421,868$ & $3,262,407$ & $3,633,149$ & $3,872,930$ \\
\hline variation & $+10.5 \%$ & $+7.8 \%$ & $+14.8 \%$ & $+1.3 \%$ \\
\hline
\end{tabular}

- the no-switch cost is a hypothetical model in which switches would not have been performed and patients would have continued their previous $\mathrm{bDMARD}$ throughout the respective year, before the first switch was made composed in 2019 from simple switches (10,989,729 lei), multiple switches $(1,214,788$ lei) and initiations followed by switch $(204,912$ lei); in 2018, from simple switches $(3,346,940$ lei), multiple switches $(188,931$ lei) and initiations followed by switch $(97,278$ lei); in 2017 , from simple switches $(3,060,174$ lei), multiple switches $(101,741$ lei) and initiations followed by switch (100,493 lei); in 2016, from simple switches (2,302,188 lei), multiple switches (60,531 lei) and initiations followed by switch $(59,149$ lei).

\section{CONCLUSIONS}

Given the limited resources of the health system, rheumatologists are interested in reducing the costs of modern treatments for chronic inflammatory rheumatic diseases, given that the therapeutic targets are obtained and maintained. Interest for therapeutic costs had led physicians to recommend reduction of therapeutic exposure (tapering) in selected cases, a strategy which corresponds to the medical need to reduce risks of adverse events, simultaneously reducing the costs. Switching of $\mathrm{b} / \mathrm{tsDMARDs}$ for medical reasons (adverse events or failure to reach the therapeutic target with the previous b/tsDMARD) corresponds to the principle of higher priority of efficacy over efficiency, and it actually leads to savings, a fact confirmed by RRBR data, as it prevents wasting resources on medically inefficient drugs. Additionally, cost reduction can be facilitated by stimulating the use of bDMARD biosimilars, a fact confirmed by the presented RRBR data. If the real price difference in Romania of biosimilars compared to the originals would reflect the significant difference between these prices in other health systems (as in Nordic countries), the impact on cost reduction would be even higher. The emergence of new therapies and biosimilar bDMARDs also induced the phenomenon of price erosion of originator bDMARDs, with contributes to maintaining expenses, lowering the cost per patient and treating more patients as long as the therapeutic target is reached and maintained.

Conflict of interest: none declared Financial support: none declared

\section{REFERENCES}

1. Brennan A, Bansback N, Nixon R, Madan J, Harrison M, Watson $\mathrm{K}$ et al. Modelling the cost effectiveness of TNF-alpha antagonists in the management of rheumatoid arthritis: Results from the British Society for Rheumatology Biologics Registry. Rheumatology (Oxford). 2007;46(8):1345-54.

2. Kvamme MK, Lie E, Kvien TK, Kristiansen IS. Two-year direct and indirect costs for patients with inflammatory rheumatic joint

diseases: Data from real-life follow-up of patients in the NORDMARD registry. Rheumatology (Oxford). 2012;51(9):1618-27.

3. Vermeer M, Kievit W, Kuper HH, Braakman-Jansen LM, Bernelot Moens HJ, Zijlstra TR et al. Treating to the target of remission in early rheumatoid arthritis is cost-effective: results of the DREAM registry. BMC Musculoskelet Disord. 2013;14:350. 
4. Codreanu C, Mogosan C, lonescu R. Biologic therapy in rheumatoid arthritis: results from the Romanian Registry of Rheumatic Diseases one year after initiation. Farmacia. 2014;62(6):1089-96.

5. Pentek M, Poor G, Wiland P, Olejarova M, Brzosko M, Codreanu C et al. Biological therapy in inflammatory rheumatic diseases: Issues in Central and Eastern European countries. Eur J Health Econ. 2014; 15 Suppl 1:S35-43.

6. Cardenas M, de la Fuente S, Castro-Villegas MC, Romero-Gomez M, Ruiz-Vilchez D, Calvo-Gutierrez J et al. Cost-effectiveness of clinical remission by treat to target strategy in established rheumatoid arthritis: Results of the CREATE registry. Rheumatol Int. 2016;36(12):1627-32.

7. Inotai A, Prins CPJ, Csanadi M, Vitezic D, Codreanu C, Kalo Z. Is there a reason for concern or is it just hype? -A systematic literature review of the clinical consequences of switching from originator biologics to biosimilars. Expert Opin Biol Ther. 2017; 17(8):915-26.

8. Codreanu C, Mogosan C, Popescu C, Paveliu MS. Analysis of the Indirect Costs of Rheumatoid Arthritis in Romania. Biomed Res Int. 2019;2019:9343812.

9. van de Laar CJ, Oude Voshaar MAH, Vonkeman HE. Costeffectiveness of different treat-to-target strategies in rheumatoid arthritis: Results from the DREAM registry. BMC Rheumatol. 2019; 3:16.

10. Smolen JS, Landewe RBM, Bijlsma JWJ, Burmester GR, Dougados M, Kerschbaumer A et al. EULAR recommendations for the management of rheumatoid arthritis with synthetic and biological disease-modifying antirheumatic drugs: 2019 update. Ann Rheum Dis. 2020. 